\begin{tabular}{|c|c|c|c|}
\hline \multirow{2}{*}{$\begin{array}{r}\text { Case Reports in } \\
\text { Gastroenterology }\end{array}$} & \multicolumn{2}{|c|}{ Case Rep Gastroenterol 2016;10:257-263 } & \multirow[b]{2}{*}{$\begin{array}{l}\text { Karger } \\
\text { Open access }\end{array}$} \\
\hline & $\begin{array}{l}\text { DOI: } 10.1159 / 000446767 \\
\text { Publisnea oninne: June 0, } 2016\end{array}$ & $\begin{array}{l}\text { (c) } 2016 \text { The Author(s) } \\
\text { Published by S. Karger AG, Basel } \\
\text { www.karger.com/crg }\end{array}$ & \\
\hline & $\begin{array}{l}\text { This article is licensed under } \\
\text { International License (CC BY- } \\
\text { Usage and distribution for com }\end{array}$ & $\begin{array}{l}\text { nons Attribution-NonCommercia } \\
\text { ger.com/Services/OpenAccessLic } \\
\text { uires written permission. }\end{array}$ & \\
\hline
\end{tabular}

\title{
Slow-Growing Early Adenocarcinoma Arising from Traditional Serrated Adenoma in the Duodenum
}

\author{
Yoon Kyoo Park Woo Jin Jeong Gab Jin Cheon \\ Division of Gastroenterology, Department of Internal Medicine, Gangneung Asan \\ Hospital, University of Ulsan College of Medicine, Gangneung-si, Republic of Korea
}

\section{Keywords}

Serrated adenoma $\cdot$ Duodenum $\cdot$ Duodenal adenocarcinoma

\begin{abstract}
Serrated polyps are classified into 3 distinct types: hyperplastic polyp, sessile serrated adenoma, or transitional serrated adenoma. A serrated adenoma is a precursor lesion for colorectal carcinoma. Serrated polyps are commonly found in the colorectum but have rarely been described in other parts of the gastrointestinal tract. Serrated adenomas in the small intestine may represent aggressive lesions with high malignant potential, according to some reports. A 66-year-old man with no significant medical history underwent esophagogastroduodenoscopy (EGD) for general examination. He had a 1-cm sized, Yamada type IV polyp, with focal white patch in the second portion of the duodenum. The biopsy result revealed gastric metaplasia and chronic inflammation. He wanted regular follow -up examinations. The follow-up EGDs were done every year. There were no changes in the shape and size of the polyp. The pathologic findings were unchanged. Then, he underwent EGD for general medical check-up again 5 years after the first detection. The size of the polyp was slightly increased. The biopsy result revealed serrated polyp, unclassified. Endoscopic mucosal resection was done. The pathologic result revealed a $0.8 \times 0.5-\mathrm{cm}$ sized, well differentiated tubular adenocarcinoma. Carcinomas are multifocally spread on the traditional serrated adenoma, and the proportion of the adenocarcinoma component is approximately $50 \%$. The tumor had
\end{abstract}


Park et al.: Slow-Growing Early Adenocarcinoma Arising from Traditional Serrated Adenoma in the Duodenum

invaded the lamina propria but confined to the mucosa. The resection margins were negative, and no lymphovascular invasion or perineural invasion was seen. Abdominal pelvic computed tomography and positron emission tomography showed no other solid organ involvement or metastasis. Surveillance follow-up EGDs were done after 3 months and 1 year. There was no evidence of recurrence.

\section{Introduction}

Several types of polyps can occur in the duodenum. Ectopic gastric mucosa and polyps related to Brunner's gland hyperplasia are the most common polyps. Most of the duodenal polyps are nonneoplastic [1-3].

Serrated polyps are characterized by infolding of the crypt epithelium, resulting in a saw-tooth appearance. A polyp with serrated morphological features has been classified histologically as hyperplastic polyp in the past. Until the late 1990s, colorectal polyps were generally divided into two major subtypes: hyperplastic polyps and adenomatous polyps. In 1990, Longacre and Fenoglio-Preiser [4] first used the term 'serrated adenoma' to describe a serrated polyp that had rather uniform dysplastic cytology. The term 'serrated' came from the observation of the saw tooth-shaped infoldings of the surface and crypt epithelium of these polyps that was similar to that of hyperplastic polyps. Serrated polyps are now classified into 3 distinct types by histologic and genetic characteristics: hyperplastic polyp, sessile serrated adenoma, and transitional serrated adenoma (TSA). A serrated adenoma is a precursor lesion for colorectal carcinoma (CRC). The serrated neoplasia pathway has been associated with carcinogenesis of serrated adenoma, which is different from the traditional adenoma-carcinoma sequence [5, 6]. The serrated neoplasia pathway accounts for $10 \sim 15 \%$ of colorectal carcinomas.

Serrated polyps are commonly found in the colorectum but have rarely been described in other parts of the gastrointestinal tract. Serrated polyps are very rare in the duodenum. The first case of TSA of the duodenum was reported in 2004 [7]. Serrated polyps in the small intestine have been reported sporadically. Because of the rarity of identifying such a lesion in the small bowel, the natural history, prognosis, and appropriate management recommendations are unclear. Serrated adenomas in the small intestine may represent more aggressive lesions with high malignant potential than those in the colon and rectum, according to some reports. We should consider the existence of serrated adenoma of the duodenum and its higher virulence.

We report a case of a slow-growing early adenocarcinoma arising from a traditional serrated adenoma of the duodenum, which was diagnosed and treated by an endoscopic mucosal resection.

\section{Case}

A 66-year-old man with no significant medical history underwent esophagogastroduodenoscopy (EGD) for general examination (fig. 1). He had a 1-cm sized, Yamada type IV polyp in the second portion of the duodenum. It was an elevated mucosal lesion with focal white patch and was located at the proximal site of the major papilla. An endoscopic biopsy was taken. The biopsy result revealed gastric metaplasia and chronic inflammation. The patient wanted regular follow-up examinations. 
Park et al.: Slow-Growing Early Adenocarcinoma Arising from Traditional Serrated Adenoma in the Duodenum

The follow-up EGD was done after 2 years (fig. 2). There was no change in the shape and size of the polyp. The pathologic finding was unchanged. We recommended the patient to resect the polyp; however, he preferred regular follow-up examination every year. There was no change in the shape, size, and pathologic finding of the polyp for two consecutive years. He underwent another EGD for general medical check-up 3 years later ( 5 years after the first detection) (fig. 3). The size of the polyp was slightly increased, but the shape of the polyp was not changed. The biopsy result revealed a serrated polyp, unclassified. We decided to resect the polyp because of neoplastic change in histology.

Endoscopic mucosal resection was done (fig. 4). The lesion was raised by means of a submucosal injection of hypertonic saline tinted with indigo carmine and resected by using a snare. Hemoclips were applied on the resected base for the prevention of bleeding and perforation. There were no complications. The pathologic result revealed a $0.8 \times 0.5-\mathrm{cm}$ sized, well differentiated tubular adenocarcinoma (fig. 5). Carcinomas are multifocally spread on the traditional serrated adenoma, and the proportion of adenocarcinoma component is approximately 50\%. The tumor had invaded the lamina propria but had been confined to the mucosa. The resection margins were negative. No lymphovascular invasion or perineural invasion was seen. Abdominal pelvic computed tomography and positron emission tomography showed no other solid organ involvement or metastasis. Surveillance follow-up EGDs were done after 3 months and 1 year. There was a scar change. The pathologic result showed no evidence of recurrence. He is now in good health and we will perform surveillance followup EGD after 1 year.

\section{Discussion}

Benign serrated polyps are commonly found in the colorectum but have rarely been described in other parts of the gastrointestinal tract. The first case of TSA of the duodenum was reported in 2004 [7]. The patient was a 78-year-old male with familial adenomatous polyposis. Eight years after colectomy, he developed a silent jaundice. A cholangiography showed a 2 -cm long stricture in the distal bile duct. The surgical specimen showed a papillary tumor juxtaposing the papilla of Vater. Histology disclosed an adenomatous growth with unlocked saw tooth-like glands with high-grade dysplasia. No invasive carcinoma was found.

More recently, TSAs have also been detected in the upper digestive tract. TSAs were found in the esophagus, the stomach [8], the duodenum [9], the pancreas [10], and the gallbladder [11]. Increased awareness of the existence of serrated neoplasms in the upper digestive tract may result in similar cases being reported in the future. Rubio's [12] review indicated that $53.4 \%(n=39)$ of the 73 TSAs of the upper digestive tract showed a simultaneously growing invasive carcinoma. Following that original publication [13-15], 35 additional cases of TSA of the duodenum appeared in the literature; $28.6 \%(n=10)$ of the 35 cases showed invasive growth. Of 73 cases of TSA of the upper digestive tract reported in the literature so far, $53.4 \%(\mathrm{n}=39)$ had invasive carcinoma. Although the causes for this aggressive behavior remains elusive, it would appear that not only the degree of cellular severity, but also the histological configuration (i.e., with unlocked serrations) might have played a particular role in their virulence. In Rosty et al's study [13], high-grade dysplasia was present in six of the serrated adenomas (46\%). One case was an adenocarcinoma resembling a serrated adenocarcinoma of the colorectum, with an adjacent serrated adenoma. This high frequency of high-grade dysplasia suggests that these adenomas may represent aggressive lesions with high malignant potential. Serrated adenomas in the small intestine may repre- 
Park et al:: Slow-Growing Early Adenocarcinoma Arising from Traditional Serrated Adenoma in the Duodenum

sent a distinct morphological subtype of adenoma with a biological significance that is different from those in the colon and rectum.

In the current case, the duodenal polyp was a very slow-growing polyp. Endoscopically there was only minimal change in polyp size and shape over 5 years. However, histologically traditional serrated adenoma developed and it had invasive carcinoma simultaneously. It is consistent with other reports that serrated adenoma in the small bowel is more virulent than those in the colon. TSAs of the duodenum should be radically excised, either endoscopically or surgically to rule out the possibility of a synchronously growing invasive adenocarcinoma or to prevent cancer progression.

In conclusion, this present case distinctively showed a slow growth but had adenocarcinoma arising from serrated adenoma of the duodenum. We should consider the existence of serrated adenoma of the duodenum and excise it radically owing to its high virulence.

\section{Statement of Ethics}

The authors have no ethical conflicts to disclose.

\section{Disclosure Statement}

The authors have no conflicts of interest to disclose.

\section{References}

1 Chong KC, Cheah WK, Lenzi JE, et al: Benign duodenal tumours. Hepatogastroenterol 2000;47:12981300.

2 Zollinger RM, Sternfeld WC, Schreiber H: Primary neoplasms of the small intestine. Am J Surg 1986;151:654-658.

-3 Jepsen JM, Persson M, Jakobsen T, et al: Prospective study of prevalence and endoscopic and histopathologic characteristics of duodenal polyps in patients submitted to upper endoscopy. Scand J Gastroenterol 1994;29:483-487.

-4 Longacre TA, Fenoglio-Preiser CF: Mixed hyperplastic adenomatous polyps/serrated adenomas. A distinct form of colorectal neoplasia. Am J Surg Pathol 1990;14:524-537.

5 Torlakovic E, Snover DC: Serrated adenomatous polyposis in humans. Gastroenterology 1996;110:748755.

-6 Snover DC, Jass JR, Fenoglio-Preiser C, et al: Serrated polyps of the large intestine: a morphologic and molecular review of an evolving concept. Am J Surg Pathol 2005;124:380-391.

7 Rubio CA: Serrated adenoma of the duodenum. J Clin Pathol 2004;57:1219-1221.

$>8$ Rubio CA, Befrits R, Ericsson J: Serrated adenoma of the esophagus. Anticancer Res 2013;33:17431745.

-9 Iwamuro M, Hori K, Tanaka T, Okada H: Serrated polyp of the duodenum. Gastrointest Endosc 2015;82:966-967.

10 Rubio CA: Serrated neoplasia of the stomach: a new entity. J Clin Pathol 2001;54:849-853.

11 Rubio CA, Grimelius L, Von Sivers K, et al: Intraductal serrated adenoma of the pancreas. A case report. Anticancer Res 2005;25:3099-3102.

12 Rubio CA: Traditional serrated adenomas of the upper digestive tract. J Clin Pathol 2016;69:1-5.

13 Rosty C, Campbell C, Clendenning M, et al: Do serrated neoplasms of the small intestine represent a distinct entity? Pathological findings and molecular alterations in a series of 13 cases. Histopathology 2015;66:333-342.

14 Srivastava A, Rege TA, Kim KM, et al: Duodenal serrated adenomas: evidence for serrated carcinogenesis in the proximal small intestine (abstract No. 705). Mod Pathol (Supplement USCAP 100th Annual Meeting) 2000;13:103-106. 


\section{Case Reports in Gastroenterology}

\begin{tabular}{l|l}
\hline Case Rep Gastroenterol 2016;10:257-263 \\
\hline $10.1159 / 000446767$ & $\begin{array}{l}\text { @ 2016 The Author(s). Published by S. Karger AG, Basel } \\
\text { www.karger.com/crg }\end{array}$ \\
\hline
\end{tabular}

Park et al: Slow-Growing Early Adenocarcinoma Arising from Traditional Serrated Adenoma in the Duodenum

15 Taggart M, Rashid A, Estrella J, et al: Serrated polyps of the extracolonic gastrointestinal tract. Histologic findings and genetic alterations (abstract No. 753). Mod Pathol (Supplement USCAP 100th Annual Meeting) 2000;13:212-214.

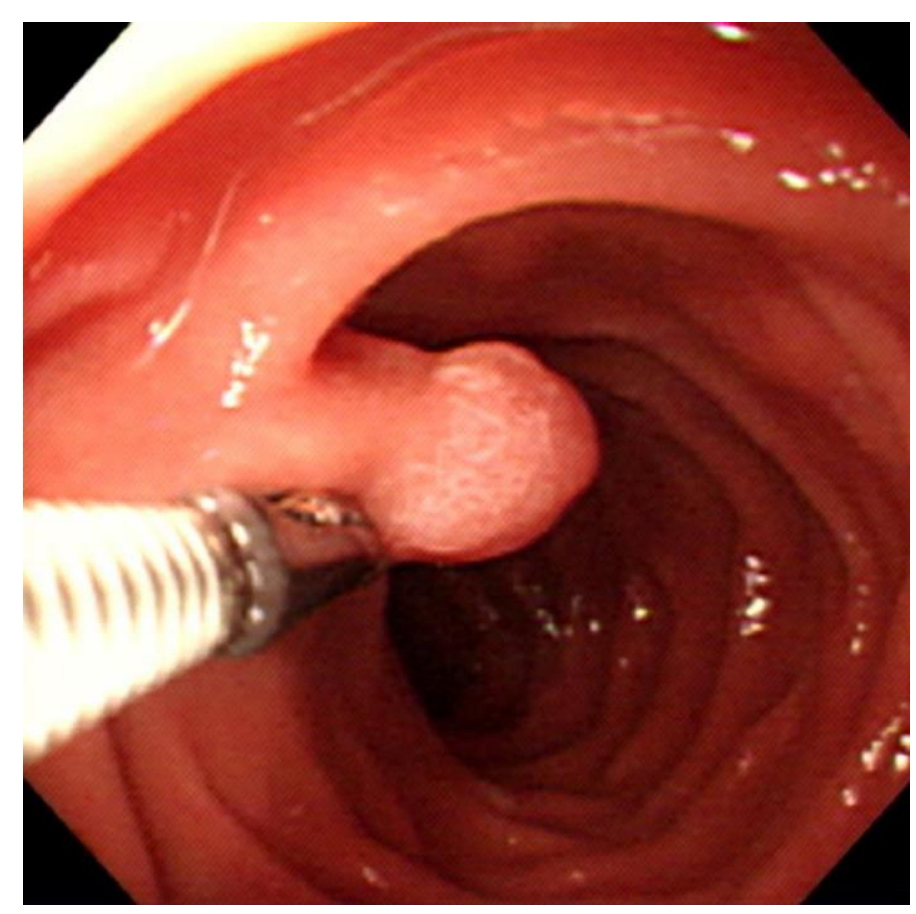

Fig. 1. Endoscopic finding of the duodenal polyp. A 1-cm sized, Yamada type IV polyp with white patch in the second portion of the duodenum. 


\section{Case Reports in Gastroenterology

\begin{tabular}{l|l}
\hline Case Rep Gastroenterol 2016;10:257-263 \\
\hline $10.1159 / 000446767$ & $\begin{array}{l}\text { C 2016 The Author(s). Published by S. Karger AG, Basel } \\
\text { www.karger.com/crg }\end{array}$ \\
\hline
\end{tabular} \\ Park et al: Slow-Growing Early Adenocarcinoma Arising from Traditional Serrated Adenoma in the Duodenum}

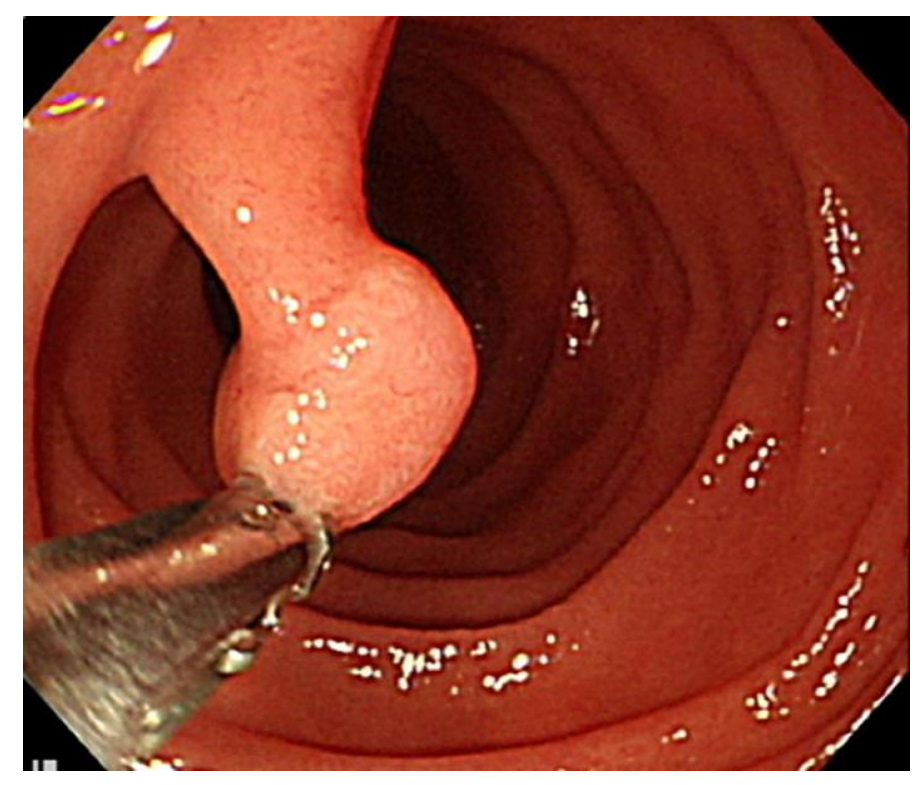

Fig. 2. Endoscopic finding after 2 years. There was no interval change on the shape and size of the polyp.

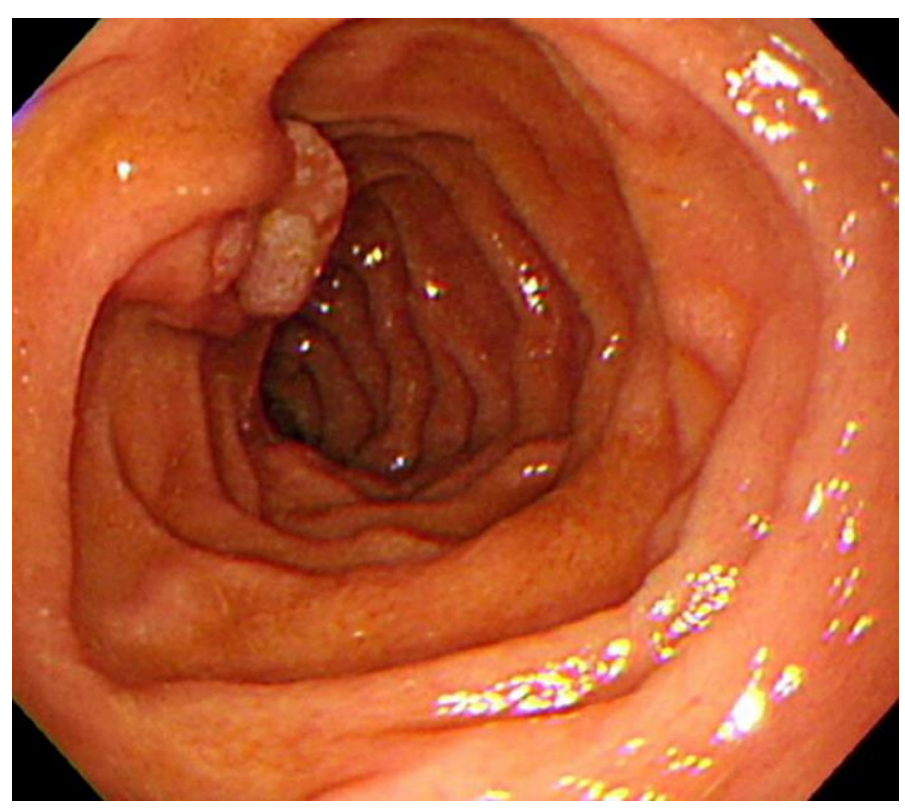

Fig. 3. Endoscopic finding after 5 years. The size was mildly increased. 


\section{Case Reports in
Gastroenterology

\begin{tabular}{l|l}
\hline Case Rep Gastroenterol 2016;10:257-263 \\
\hline $10.1159 / 000446767$ & $\begin{array}{l}\text { @ 2016 The Author(s). Published by S. Karger AG, Basel } \\
\text { www.karger.com/crg }\end{array}$ \\
\hline
\end{tabular}

Park et al: Slow-Growing Early Adenocarcinoma Arising from Traditional Serrated Adenoma in the Duodenum

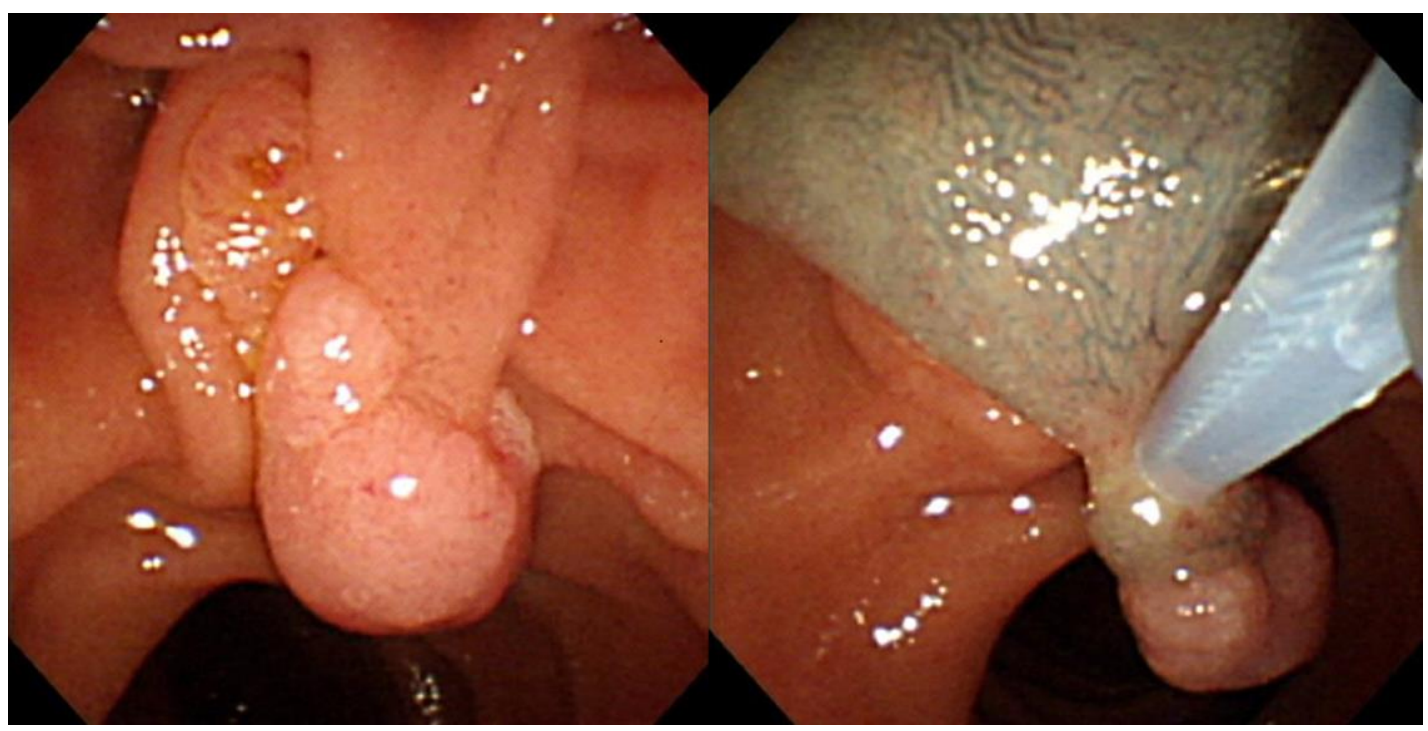

Fig. 4. Endoscopic mucosal resection finding. Snare resection was performed after submucosal injection of hypertonic saline tinted with indigo carmine.
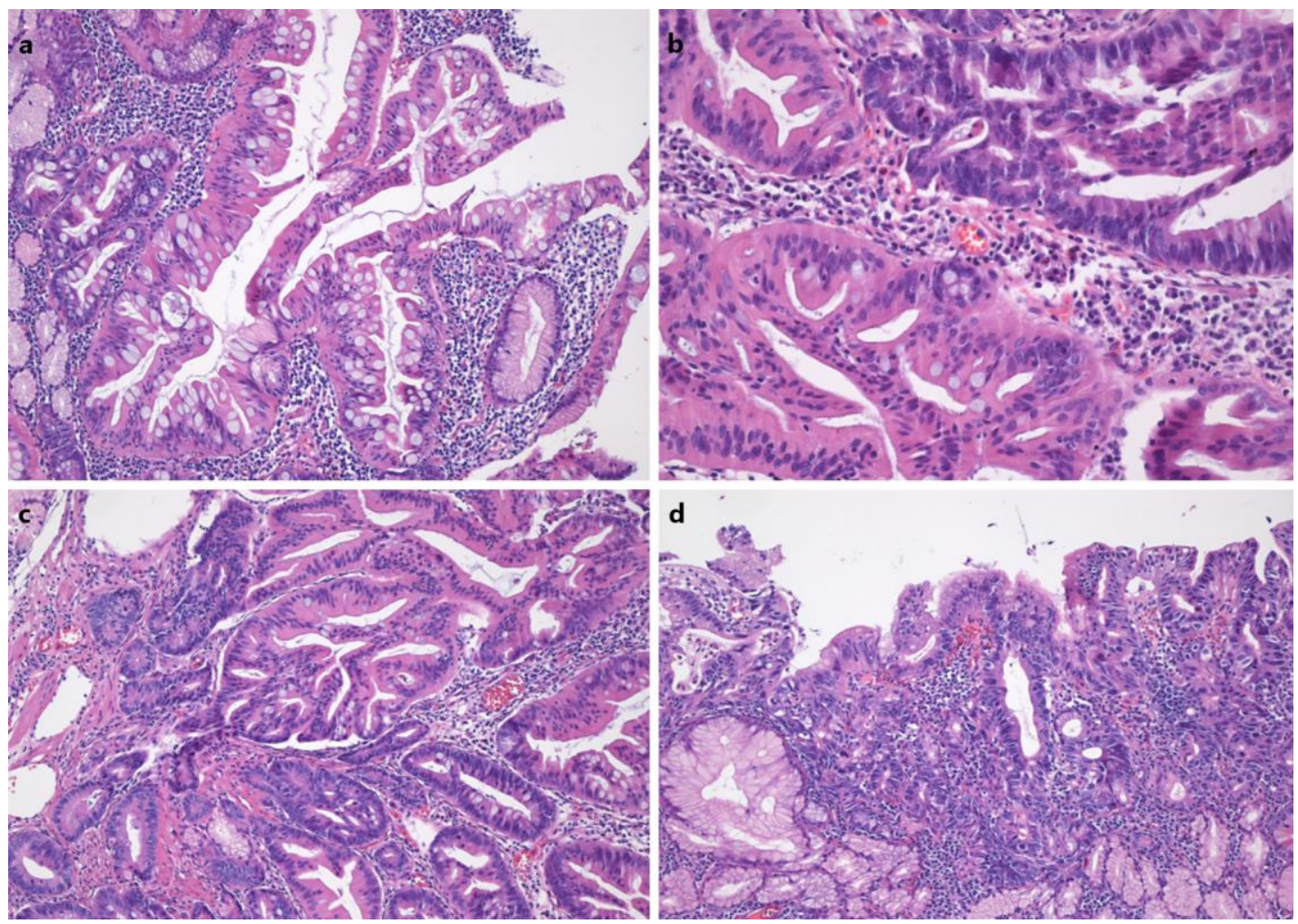

Fig. 5. Microscopic findings. Proliferation of the mucosal epithelium with serrated feature (a), ectopic crypt (b), and high-grade dysplasia (c). Well-differentiated tubular adenocarcinoma with lamina propria invasion. a, c, d H\&E. $\times 100$. b H\&E. $\times 200$. 